Vol.3 No.2 Hal. 114-119

September 2020

\title{
Perspektif Orang Tua Terhadap Kesetaraan Gender dan Inklusi Sosial Dalam Meningkatkan Kualitas Pendidikan Anak
}

\author{
Purwati $^{(1)}$, Juliati ${ }^{(2)}$, Irma Dewi Isda ${ }^{(3)}$ \\ Pendidikan Bahasa Inggris dan Pendidikan Guru Sekolah Dasar \\ Fakultas Keguruan Dan Ilmu Pendidikan \\ Universtias Samudra
}

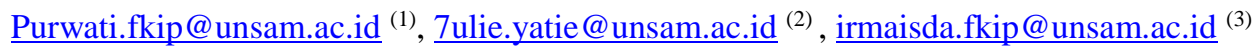

\begin{abstract}
ABSTRAK
Studi ini fokus pada permasalahan perspektif orang tua terhadap kesetaraan gender dan inklusi sosial dalam upaya meningkatkan kualitas pendidikan anak. Persfektip orang tua terhadap kesamaan pemberian hak kepada anak dalam mengenyam pendidikan dapat dipengaruhi oleh peraturan khas yang berlaku pada suatu daerah. Pola fikir orang tua dalam menentukan keputusan dianalisa melalui konsep Bourdieu yaitu habitus, kelas, modal, dan ranah. Penelitian ini dilaksanakan di Gampong Batee Puteh, Langsa. Metode yang diterapkan dalam penelitian ini adalah deskriftip kualitatif dengan tujuan untuk mengetahui lebih dalam pandangan responden terhadap masalah yang terjadi melalui ungkapan-ungkapan dan fakta-fakta dalam situasi yang natural. Data diperoleh melalui observasi dan wawancara secara mendalam. Berdasarkan hasil penelitian diperoleh informasi bahwa setiap anak baik laki-laki maupun perempuan memiliki hak yang sama dalam pendidikan. Lembaga penyelenggara pendidikan dengan fokus pendidikan agama Islam menjadi pilihan bagi orang tua sebagai pendidikan yang harus dijalani oleh anak. Perbedaan pola fikir orang tua dalam memaknai pendidikan, tujuan, fungsi, serta manfaat yang diperoleh dari pendidikan didasari oleh ide yang muncul secara alami, perbedaan tingkat pendidikan, hubungan sosial yang terjalin dalam masyarakat, serta pemertahanan posisi keberadaan suatu keluarga dalam lingkungan sosial.
\end{abstract}

Kata Kunci : Orang Tua, Gender, Pendidikan

\begin{abstract}
This study focused on parents' perception toward gender equality and social inklusion to improve quality of child education. Parents' perception to given the same right in education can be influenced by typical rules that applied in one area. Parents' ideas in maing decision analyze by Bourdieu's concepts namely habitus, class, modal, and area. This research was conduct at Gampong Batee Puteh, Langsa. Descriptive qualitative method had been applied as the method of this research to got the deep information about the problems found through speechs and fact in a natural setting. The data got through observation and deep interview. Based on the result of the research show that every child both boys and girls got the same right in education. Islamic education field is the first choice for the parents as the place for their children to get the education. The difference ideas about education, the aim, and function between father and mother depend on the natural ideas that everyone have, the different of education level, social interaction in society, and family position in society.
\end{abstract}

Keywords: Parents, Gender, Education 
Purwati, Juliati, Isda Irma D : Perspektif Orang Tua Terhadap Kesetaraan Gender dan Inklusi Sosial Dalam Meningkatkan Kualitas Pendidikan Anak

\section{PENDAHULUAN}

\section{Latar Belakang}

Lembaga yang paling utama dalam membentuk pribadi yang baik bagi anak adalah keluarga. Tanggungjawab yang besar terhadap pendidikan anak ada pada keluarga sementara lembaga lain yang turut berperan serta adalah lembaga pemerintah maupun swasta yang bergerak dalam bidang pendidikan (Sochib dalam Muthmainah 2012). Pendidikan merupakan hal yang sangat penting untuk meningkatkan pola fikir, kemandirian, dan kemampuan dalam mengambil sikap. Proses yang berlangsung sepanjang hayat dan berguna untuk menyelaraskan kondisi dalam diri dan luar diri merupakan wujud pendidikan yang dapat dilihat langsung perubahannya terhadap diri seseorang (Muhammad Saroni 2011: 10). Orang tua harus membekali anak dengan pendidikan yang baik secara spiritual maupun sosial. Namun dalam proses pencapaiannya, sering muncul kendala yang merupakan bahagian dari peraturan yang berlaku pada suatu tempat maupun keyakinan masyarakat sehingga menghambat tercapainya tujuan tersebut, salah satunya adalah gender. Keterkaitan gender dengan qanun pada masyarakat di gampong Batee Puteh, Langsa, Aceh menjadi hal yang menarik untuk diperbincangkan. Syariat Islam yang diterapkan di Aceh bukanlah hal yang aneh karena aturan tersebut berdasarkan Islam (Arivi. A dalam T.Saiful 2016). Perbedaan antara kaum perempuan dan laki-laki menjadi salah satu point yang tertera dalam qanun tersebut. Hal tersebut dapat mempengaruhi pola fikir seseorang dalam memaknainya yang berkaitan dengan habitus. Habitus yang berarti kebiasaan dalam bahasa Latin merupakan konsep dari Bourdieu yang mengungkapkan "akal sehat" dimana ada beberapa pembagian kelas yaitu usia, jenis kelamin, dan kelas sosial (Bourdieu, 1990). Selain habitus, konsep lain yaitu kelas, modal, dan ranah/arena dapat mengkaji bagaimana perspektif tersebut akan muncul pada diri seseorang. Masalah pendidikan, gender, dan juga masalah sosial dalam masyarakat merupakan satu kesatuan yang tidak dapat dipisahkan. Fenomena tersebut sering ditemukan pada masyarakat. Salah satunya adalah masih banyak masyarakat yang memandang bahwa adanya batasan-batasan antara perempuan dan laki-laki dalam melakukan suatu tindakan atau aktifitas. Patriarki (English: patriarchy) adalah sebuah sistem struktur sosial dan prakteknya dimana laki-laki mendominasi, menekan dan mengeksploitasi perempuan (Walby: 1990).

\section{Perumusan Masalah}

Berdasarkan uraian di atas terhadap fenonema yang diperoleh dalam masyarakat, maka permasalahan yang akan dibahas adalah bagaimana perspektif orang tua terhadap kesetaraan gender dan inklusi sosial dalam upaya meningkatkan kualitas pendidikan anak. Hal tersebut dianggap menarik untuk diketehui lebih dalam karena adanya keterkaitan sudut pandang orang tua dengan pendidikan anak.

\section{Tujuan Penelitian}

Penelitian ini bertujuan untuk menggali informasi lebih dalam tentang perspektif orang tua terhadap kesetaraan gender dan inklusi sosial dalam meningkatkan kualitas pendidikan anak.

\section{Manfaat Penelitian}

Melalui kajian ini akan dilihat bagaimana orang tua akan membentuk pola fikir terhadap usaha meningkatkan kualitas pendidikan anak.

\section{METODE PENELITIAN}

Metode yang diterapkan dalam penelitian ini adalah dekriptif kualitatif. Metode tersebut diterapkan guna mengetahui lebih dalam pandangan responden terhadap masalah yang terjadi melalui ungkapan-ungkapan dan fakta dalam situasi yang alami (Moleong Lexy J, 2002:6). 
Purwati, Juliati, Isda Irma D : Perspektif Orang Tua Terhadap Kesetaraan Gender dan Inklusi Sosial Dalam Meningkatkan Kualitas Pendidikan Anak

\section{Populasi dan Sampel}

Populasi dalam penelitian ini adalah seluruh keluarga di Gampong Batee Puteh yang memiliki anak dengan jenis kelamin laki-laki dan perempuan dan masih bersekolah. Sampel diambil dengan menggunakan teknik purposive sesuai dengan tujuan penelitian. Jumlah sampel adalah 5 keluarga.

\section{Teknik Pengumpulan Data}

Teknik pengumpulan data dilakukan melalui beberapa tahapan yaitu, observasi, wawancara mendalam, dan dokumentasi.

\section{Teknik Analisa Data}

Untuk memperoleh hasil penelitian, maka data yang diperoleh dianalisa melalui tahapantahapan sebagai berikut: reduksi data, penyajian data, penyimpulan, dan verifikasi

\section{HASIL DAN PEMBAHASAN}

\section{Hasil}

Perspektif orang tua terhadap kesetaraan gender dalam upaya meningkatkan pendidikan bagi anak dapat ditinjau melalui konsep Bourdieu, yang meliputi konsep habitus, kelas, modal, dan ranah/arena. Keempat konsep tersebut ditemukan berdasarkan data yang telah diperoleh. Konsep habitus menggambarkan adanya sebuah ide pada setiap manusia yang berasal dari dirinya sendiri. Habitus tersebut akan berbeda pada setiap individu. Pada konsep kelas menunjukkkan bahwa ketika seseorang berada pada tingkatan yang lebih tinggi, seperti tingkat pendidikan maka akan muncul persepsi yang berbeda dalam memaknai pendidikan itu sendiri. Dalam konsep berikutnya yaitu konsep modal, yang menggamparkan bagaimana hubungan sosial terjalin dan dapat mempengaruhi aspek apa yang harus dilakukan dan yang tidak boleh dilakukan karena adanya pengaruh dalam pola hubungan tersebut. Konsep yang terakhir yaitu ranah/arena yang akan tetap menjaga atau bahkan menaikkan posisi seseorang kedalam kelas-kelas sosial.

\section{Pembahasan}

\section{A. Perspektif Orang Tua terhadap Kesetaraan Gender dan Inklusi Sosial melalui konsep-konsep Bourdieu \\ a.Habitus}

Setiap manusia berkeinginan untuk menjadi pribadi yang lebih baik melalui tahapan-tahapan sebagai wujud dari suatu proses. Pola fikir, prilaku, dan pengaruh dari lingkungan sekitar akan sangat mempengaruhi bagaimana tindakan yang harus dilakukan untuk mencapai tujuan. Habitus, dalam bahasa latin berarti kebiasaan menggambarkan penampilan diri yang sesuai dengan tipikal tubuh. Konsep ini bersumber dari pemikiran filsafat dan ini berarti bahawa konsep habitus bukan asli dari Bourdieu. Peran beliau adalah mengembangkan konsep tersebut. Bourdieu mengatakan bahwa satu generasi dari suatu kelas memastikan bahwa ia memproduksi dirinya dan meningggalkan hak istimewanya kepada generasi beikutnya. Hal ini tampak pada peran orang tua sebagai penuntun generasi muda untuk mencapai tujuannya, salah satunya dalam bidang pendidikan (Hidayat, 2010). Orang tua sangat berperan dalam mengembangkan bakat generasi muda. Sudut pandang orang tua menjadi salah satu penentu arah bagi anak-anaknya untuk meraih cita-cita. Pola fikir sangat dipengaruhi oleh lingkungan sekitar, salah satunya budaya yang melekat dan merupakan wujud dari kekhasan suatu daerah. Pada masyarakat gampong Batee Puteh, khususnya orang tua yang memiliki anak dengan jenis kelamin yang berbeda, laki-laki dan perempuan, mereka diberi hak yang sama dalam menuntut ilmu. Tidak ada perbedaan bagi salah satunya dalam memperoleh haknya. Namun dalam penentuan bidang fokus pendidikan, orang tua memiliki andil yang sangat besar. Cerminan makna kata "serambi" yang melekat serta wujud dari keadaan yang tercipta menjadikan hal tersebut sebagai alasan kuat bagi orang tua untuk mengharuskan anak-anak fokus pada pendidikan agama melalui lembaga pendidikan Dayah. 
Dayah merupakan lembaga pendidikan Islam tertua di Aceh dan memliki bentuk yang khas. Lembaga ini memiliki pengaruh yang sangat besar bagi masyarakat di Aceh. Tujuan dari Dayah adalah untuk membina masyarakat agar memiliki kepribadian yang sesuai dengan Islam, menjadi insan yang berguna bagi nusa, bangsa, dan agama serta menjadi manusia sebagai hamba yang dapat mengabdikan diri kepada Allah SWT (Marhamah, 2018) Pemilihan tempat untuk mengenyam pendidikan tersebut bukan tanpa alasan yang kuat. Kemajuan zaman yang dibarengi dengan perkembangan teknologi yang canggih membawa orang tua tetap berada pada budaya serambi karena budaya Aceh adalah bersumber dari Islam. Nilai moral, etika, sopan santun menjadi dasar pendidikan yang harus dimiliki oleh seorang anak baik laki-laki maupun perempuan yang nantinya akan dibarengi dengan kemajuan teknologi. Nilai-nilai tersebut wajib ada pada setiap anak agar tidak terlepas dari jati dirinya bahwa manusia adalah makhluk yang sempurna dibandingkan dengan makhlukmakhluk lainnya.Selain cerminan Islam yang menjadi landasan orang tua dalam menentukan pendidikan bagi anak, faktor lain yaitu latar belakang pendidikan orang tua dan pengaruh lingkungan sosial. Kedua hal tersebut merupakan satu kesatuan yang tidak dapat dipisahkan. Faktor-faktor tersebut berdampak pada pewarisan yang istimewa kepada generasi penerus. Faktor tersebut pula yang membuat manusia tidak kaku dan tidak menyamakan dirinya dengan manusia yang lain. Perbedaan pendapat antara kedua orang tua dalam menentukan pendidikan bagi anak tidak selalu ditekankan pada keputusan yang berada di pihak salah satunya, yaitu orang tua laki-laki atau ayah. Hak yang sama juga dimiliki oleh ibu. Dominasi akan hilang ketika seseorang berada pada satu kelas yang sama atau kelas yang lebih tinggi (Fatmawati 2020).

\section{b. Kelas}

Penentuan pendidikan bagi anak tidak selalu ditekankan pada suara dominan dalam keluarga. Sudah menjadi sebuah tradisi turun temurun bahwa dalam keluarga maka seorang ayah yang akan memegang kendali penuh termasuk salah satunya dalam menentukan pilihan dan menjatuhkan keputusan. Konsep Bourdiue mengenai kelas dapat merubah stigma yang selama ini terjadi pada masyarakat (Fatmawati 2020). Terlihat pada sebuah keluarga dimana latar belakang kelas pendidikan ibu lebih tinggi dari ayah. Hal ini dapat mengakibatkan perbedaan selera antara keduanya. Meskipun pada prinsipnya kedua orang tua setuju dengan keputusan bahwa anak-anak akan melanjutkan pendidikan di Dayah tetapi terdapat perbedaan pada saat menentukan jenis Dayah tersebut. Ibu yang memiliki pendidikan labih tinggi dari ayah akan memilih Dayah yang modern karena selain mendapatkan pendidikan agama, anak juga akan mendapatkan pengetahuan umum seperti pada sekolah nasional. Sehingga diharapkan bahwa anak akan mendapat bekal ilmu pengetahuan yang lebih banyak. Sementara ayah yang memiliki latar belakang SMA sederajat, lebih memilih Dayah tradisional. Dalam benak ayah bahwa keduanya, baik Dayah tradisional maupun Dayah modern mempunyai tujuan yang sama yaitu sama-sama membina manusia agar menjadi insan yang berguna bagi nusa, bangsa, dan agama. Tidak hanya itu, penentuan lokasi Dayah tersebut juga menjadi hal yang bertolak belakang. Bagi ibu, jika Dayah tersebut memiliki pamor yang baik meskipun terletak jauh dari tempat tinggal, maka ia akan memberikan kesempatan bagi anak untuk mengenyam pendidikan disana. Jauhnya jarak antara Dayah dengan rumah bukanlah menjadi permasalahan yang signifikan karena nantinya akan mengajarkan anak agar lebih mandiri. Anak akan dengan mudah mengatur dirinya sendiri ketika jauh dari oranag tua. Disisi yang berbeda, ayah tetap menghendaki agar Dayah yang dipilih tidak jauh dari rumah, tetap berada dikota yang sama. Alasan yang melatarbelakangi karena anak harus tetap mendapat pengawasan dari orang tua meskipun mereka mengenyam pendidikan di Dayah. Konsep kelas ini menunjukkan bahwa ranah yang berbeda akan menentukan selera yang berbeda. 
Purwati, Juliati, Isda Irma D : Perspektif Orang Tua Terhadap Kesetaraan Gender dan Inklusi Sosial Dalam Meningkatkan Kualitas Pendidikan Anak

\section{c. Modal}

Modal dalam konsep Bourdieu diartikan sebagai jaringan sosial yang dimiliki seseorang dan berfungsi untuk mendapatkan dukungan kolektif dari anggota lainnya. Jaringan tersebut terbentuk dari lembaga sosial dan berbentuk praktis. Modal sosial seperti pertemanan terjalin karena adanya ketidak terikatan antar anggota. Jika ditinjau dari konsep modal terhadap perspektif orang tua dalam memberikan hak dan kesempatan bagi anak untuk memperolah pendidikan maka dapat dilihat bahwa orang tua yang memiliki modal besar akan mengacu pada pola fikir yang jauh lebih praktis dan menyesuaikan dengan perkembangan zaman. Keinginan ibu memberikan kesempatan kepada anak agar mengenyam pendidikan tidak harus di dalam kota dengan jarak tempuh yang dekat dengan tempat tinggal melainkan untuk memilih tempat yang dianggap lebih baik berdasarkan kriteria tertentu meskipun memiliki jarak tempuh yang jauh dipengaruhi oleh hubungan sosial yang terjalin. Faktor pertemanan yang dekat mempengaruhi sudut pandang seseorang dalam menentukan suatu keputusan. Pengalaman dari anggota yang lain menjadi landasan yang sangat kuat untuk mempertahankan ide yang terbentuk. Di sisi lain, pandangan ayah untuk jarak tempuh juga dipengaruhi oleh hal yang sama. Hubungan sosial yang terjalin dalam praktis pendidikan tidak seluas dengan keanekaragaman sudut pandang dari anggota sosialnya sehingga tidak banyak pilihan dan pertimbangan dalam menentukan tempat dimana anak akan mengenyam pendidikan. Pengalaman yang diperoleh dari pertemanan yang terjalin tidak fokus pada ranah pengalaman dalam pendidikan melainkan pada bidang lain. Modal sosial yang terjalin pada seseorang terjadi secara alami. Hubungan tersebut terbentuk karena adanya kesamaan dalam bidang yang sama. Modal tersebut disebut dengan modal simbolik dimana wujudnya akan terlihat dalam bentuk kehormatan, status, otoritas, dan prestice (Fatmawati, 2020).

\section{d. Ranah/Arena}

Memberi hak yang sama kepada anak-anak dalam mengenyam pendidikan adalah bentuk ranah sosial. Ranah sosial tersebut dipertahankan karena latar belakang orang tua yang memiliki pendidikan meskipun ada perbedaan pada tingkatan pendidikan akhir yang diperoleh. Melalui pendidikan, posisi sosial sebuah keluarga akan tetap terjaga dan dapat berubah ke posisi yang lebih tinggi. Pendidikan yang baik dengan implementasinya pada masyarakat akan membawa seseorang ke posisi tertentu yang ada pada ranah sosial. Selain menginginkan agar anak-anak menjadi anak yang memliki kepribadian islami, berbakti kepada kedua orang tua, dan berbakti kepada Allah, orang tua juga menginginkan agar anakanak mereka dapat menduduki posisi-posisi sosial dalam masyarakat

\section{KESIMPULAN}

Berdasarkan permasalahan dalam penelitian ini dan data yang diperoleh maka dapat disimpulkan bahwa orang tua sebagai pemegang keputusan bagi anak dalam menempuh pendidikan tidak lagi menitik beratkan kepada salah satu anak mereka tteruttama pada anak laki-laki. Perlakuan yang sama juga diberikan kepada anak perempuan. Lembaga pendidikan Islam menjadi pilihan orang tua untuk pendidikan anak karena adanya faktor identitas yang melekat pada daerah tersebut. Landasan ide orang tua dalam memaknai pendidikan, gender, dan inklusi sosial digambarkan melalui konsep Bourdiue yang terdiri dari empat konsep yaitu, habitus, kelas, modal, dan ranah.

\section{DAFTAR PUSTAKA}

Bogdan, R., \& Taylor, S. J. (1992). Pengantar Metode Penelitian Kualitatif Suatu Pendekatan Fenomenologis terhadap ilmu-ilmu Sosial, terjemahan Arief Furchan. Surabaya: Usaha Nasional.

Fatmawati, I. N. (2020). "Pierre Bourdieu dan Konsep Dasar Kekerasan Simbolik" dalam Jurnal Politik dan Sosial Kemasyarakatan, 12(1): 41-60 
Purwati, Juliati, Isda Irma D : Perspektif Orang Tua Terhadap Kesetaraan Gender dan Inklusi Sosial Dalam Meningkatkan Kualitas Pendidikan Anak

Hidayat, S. (2010). "Teori Sosial Pierre Boudieu dan Sumbangannya Terhadap Penelitian Sastra" dalam Jurnal METASASTRA, 1 (1): 43-52

Lexy, J. M. (2000). Metode penelitian Kualitatif Bandung: Rosda Karya.

Marhamah. (2018). "Pendidikan Dayah dan Perkembangannya di Aceh" dalam At-Ta'dib: Jurnal Ilmiah Pendidikan Agama Islam, 10(1): 71-91

Mutmainah. (2012). "Peran Orang Tua dalam Menumbuhkan Pribadi Anak yang Androgynius Melalui Kegiatan Bermain" dalam Jurnal Pendidikan Anak, 1(1): 103111

Pierre Bourdieu. (19190). In Other Words: Essays Towards a Reflexive Sociology. Cambridge: Polity Press

Saiful, T. (2016). "Gender Perspektif dalam Formalisasi Syariat Islam di Aceh" dalam Kanun Jurnal Ilmu Hukum, 18(2): 235-263

Saroni, M. (2011). “Kesetaraan Gender” dalam Jurnal Psikologi, 3: 152-173

\begin{tabular}{|l|l|l|l|}
\hline Accepted Date & Revised Date & Decided Date & Accepted to Publish \\
\hline 18 Agustus 2020 & 10 Agustus 2020 & 23 Agustus 2020 & Ya \\
\hline
\end{tabular}

